\title{
GENETIC IDENTITY DETERMINES RISK OF POST-SETTLEMENT MORTALITY OF A MARINE FISH
}

\author{
Laurent Vigliola, ${ }^{1,4}$ Peter J. Doherty,${ }^{2}$ Mark G. Meekan,,${ }^{1}$ Devin M. Drown, ${ }^{3}$ M. Elizabeth Jones, ${ }^{3}$ \\ AND Paul H. Barber ${ }^{3}$ \\ ${ }^{1}$ Australian Institute of Marine Science, P.O. Box 40197, Casuarina MC Darwin NT 0811 Australia \\ ${ }^{2}$ Australian Institute of Marine Science, PMB 3, Townsville MC Qld 4810 Australia \\ ${ }^{3}$ Boston University Marine Program, 7 MBL Street, Woods Hole, Massachusetts 02543 USA
}

\begin{abstract}
Longitudinal sampling of four cohorts of Neopomacentrus filamentosus, a common tropical damselfish from Dampier Archipelago, Western Australia, revealed the evolution of size structure after settlement. Light traps collected premetamorphic individuals from the water column ("settlers") to establish a baseline for each cohort. Subsequently, divers collected benthic juveniles ("recruits") at 1-3-month intervals to determine the relative impacts of post-settlement mortality during the first three months. Growth trajectories for individual fish were back-calculated from otolith records and compared with nonlinear mixed-effects models. Size-selective mortality was detected in all cohorts with the loss of smaller, slower growing individuals. Three months after settlement, recruits showed significantly faster growth as juveniles, faster growth as larvae, and larger sizes as hatchlings. The timing and intensity of post-settlement selection differed among cohorts and was correlated with density at settlement. The cohort with the greatest initial abundance experienced the strongest selective mortality, with most of this mortality occurring between one and two months after settlement when juveniles began foraging at higher positions in the water column. Significant genetic structure was found between settlers and three-month-old recruits in this cohort as a result of natural selection that changed the frequency of mtDNA haplotypes measured at the control region. The extent of this genetic difference was enlarged or reduced by artificially manipulating the intensity of size-based selection, thus establishing a link between phenotype and haplotype. Sequence variation in the control region of the mitochondrial genome has been linked to mitochondrial efficiency and weight gain in other studies, which provides a plausible explanation for the patterns observed here.
\end{abstract}

Key words: growth rates; haplotypes; larval and juvenile fish; maternal and genetic inheritance; mortality; mtDNA; otoliths; predation; recruitment; settlement; size selection.

\section{INTRODUCTION}

In the last 100 years, while industrialized fishing has reduced fish populations on a global scale (Pauly and MacClean 2003), vast effort has gone into explaining the variable and uncertain replenishment of marine populations (Sissenwine 1984). Highly variable recruitment dynamics (Roughgarden et al. 1988), spatially structured populations, high fecundity, and almost total but variable mortality of the immature (larvae and juveniles) stages (Bailey and Houde 1989) are typical of marine organisms with complex life cycles. These characteristics are common among marine invertebrates and fishes (Booth and Brosnan 1995), find analogues in the complex life cycles of macroalgae (Reed et al. 2004), and challenge our ability to understand the processes

Manuscript received 17 January 2006; revised 11 September 2006; accepted 27 October 2006. Corresponding Editor: S. R. Thorrold.

${ }^{4}$ Present address: Institut de Recherche pour le Développement, BP 70, 29280 Plouzané, France.

E-mail: laurent.vigliola@ird.fr governing the stability of marine populations (Legget and Deblois 1994).

The challenges facing marine larvae are great. Planktotrophic larvae must find nourishment and avoid predators in the ocean, then locate and colonize suitable benthos for metamorphosis into the next generation of juveniles. These requirements impose substantial risks for larval (Bailey and Houde 1989) and juvenile (Sogard 1997) stages that interact to compound uncertainties surrounding individual survival to maturity. While large-scale external factors (weather, ocean productivity, water circulation, and climate) have long been recognized as broad correlates of larval success (Bakun et al. 1982, Sinclair 1988, Cushing 1996), the recent application of individual-based models in ecology to deal with highly variable and nonlinear phenomena (Judson 1994) has improved our ability to examine the ways in which factors interact at local scales and with intrinsic attributes of the propagules to affect larval mortality.

While some sources of mortality (e.g., extreme temperatures) kill randomly, other sources (e.g., starvation, predation) produce effects that are spread unequally among individuals within a cohort. A very 
common form of selective mortality (both positive and negative) is that based on size or growth rate. Hare and Cowen (1997) describe three variations of a "growthmortality" paradigm summarized by Anderson (1988). Among individuals following the same growth path, larger size (hence age) can assist in resisting starvation and/or other acute physical stresses, or attaining a refuge from gape-limited predators. Among individuals of common age but different growth rates, larger relative size can influence the potential for cannibalism, dominance competition for limited resources, or choices by predators. Both are variants of the "bigger-is-better" hypothesis (Miller et al. 1988, Bailey and Houde 1989). Furthermore, individuals may reduce their exposure to windows of intense mortality by growing faster in either absolute and/or relative terms; variants of the "stage duration" hypothesis (Houde 1987, Leggett and Deblois 1994).

Untangling the effects of size and growth rate on larval mortality is commonly done by longitudinal resampling of the same cohort (individuals spawned during a narrow temporal window) to compare the characteristics of survivors and non-survivors in natural populations (Sogard 1997). For teleosts, this analysis is facilitated by the calcareous otoliths found in the heads of all bony fishes. These inclusions, used in balance and hearing, grow by daily accretions that deposit internal microstructures (Campana and Neilson 1985). When otolith and somatic growth are coupled, otoliths encode a permanent ontogenetic record of size-at-age that can be recovered and converted to prior sizes and/or historical growth rates by simple back calculations (Thorrold and Hare 2002), providing valuable insights to the seldom observed larval stages.

Otolith records have shown correlations between larval growth rates and cohort strength at settlement (Searcy and Sponaugle 2001, Bergenius et al. 2002, Wilson and Meekan 2002), correlations between larval growth rates and juvenile growth rates (Vigliola and Meekan 2002), and correlations between juvenile growth rates and post-settlement mortality (Searcy and Sponaugle 2001, Vigliola and Meekan 2002, McCormick and Hoey 2004). Similar effects have been observed in temperate reef fishes (e.g., Shima and Findlay 2002, Raventos and Macpherson 2005). However, it remains unclear if size-selective mortality during larval dispersal and recruitment is a consistent feature affecting most cohorts within a fish population. Furthermore, it is unclear whether selective mortality arises from density effects upon competitive interactions (Webster 2004), from food and temperature effects upon larval growth (Meekan et al. 2003), from maternal effects such as egg size and provisioning (Jones and McCormick 2002), or from genotypes that influence physiological performance (Planes and Romans 2004). These issues are not inconsequential; consistent selective mortality acting upon heritable characters may generate long lasting effects on both the demographic and the genetic compositions of surviving populations (Conover and Munch 2002, Heino and Godo 2002).

Vigliola and Meekan (2002) demonstrated positive selection in one cohort of the coral reef damselfish, Neopomacentrus filamentosus, with respect to larval size. Here, we build on these results to further extend our understanding of the consequences of size-selective mortality. First, we explore whether size-selection is a consistent feature of post-settlement mortality in this species through the examination of multiple larval cohorts with respect to both size and growth rate. Second, we examine the role of competitive interactions, environmental factors, and potential maternal effects through correlations between fish densities, growth rates and size at hatching with observed selective mortality. Finally, because of the extreme nature of the observed selective mortality, we explore the genetic consequences within the cohort that experienced the strongest natural selection to determine if and how strong size-selection can alter the genetic composition of a cohort.

\section{Methods \\ Study species}

Neopomacentrus filamentosus is a small $(<8 \mathrm{~cm})$ damselfish that is widely distributed in the IndoAustralian Archipelago (Allen 1991). Adults of this planktivorous fish are abundant in the Dampier Archipelago, Western Australia $\left(20^{\circ} 30^{\prime} \mathrm{S}, 116^{\circ} 40^{\prime} \mathrm{E}\right)$, where they occupy coral heads in shallow $(4-10 \mathrm{~m})$ water. Males guard nests of benthic eggs during Austral summer months (October to March). After four to five days of development, eggs hatch into pelagic larvae that spend an average of 18 days in the plankton (Vigliola and Meekan 2002). Settlement occurs on new moons and young recruits initially school near the bottom of large coral colonies. As they grow, recruits move up in the water column to join older juveniles and adults schooling above the coral heads. This ontogenetic habitat shift occurs at 20-25 mm, which represents one to two months of growth after settlement (Vigliola and Meekan 2002).

\section{Collection methods}

Light traps (Doherty 1987) were used to collect live presettlement reef fishes in the Dampier Archipelago over two summers. Ten traps (see Fig. 1 in Meekan et al. [2001] for trap design) were moored near the surface and cleared daily for two weeks around consecutive new moons from November 1998 to February 1999 and October 1999 to February 2000 (Vigliola and Meekan 2002). On retrieval, the content of each trap was preserved immediately in $98 \%$ methanol, which is harmless to otoliths, but essential to preserve the DNA of the incoming cohorts.

Although our sampling encompassed two entire spawning seasons for Neopomacentrus filamentosus, and eight potential lunar cohorts, presettlement fish were only abundant in catches from four months 
(November 1998, October, November, and December 1999). Benthic juveniles from the two November cohorts (1998, 1999) were collected by divers using hand nets and anaesthetic (clove oil) on three occasions (one, two, and three months) after settlement. These recruits were obtained from extensive fringing reef adjacent to the moored traps. In addition, recruits from the October and December 1999 cohorts were collected once, at three months after settlement. At each collection, sampling effort was spread along the reef and over the depth range occupied by this species to gain a representative sample of the cohort. As with settlers, recruits were preserved in alcohol.

After measurement of standard length (SL; the distance from the tip of the snout to the base of the caudal fin) fish were subsampled to select individuals for otolith analysis (see Vigliola and Meekan 2002). Light traps collected 64-381 settlers in different months (Appendix A: Table A1) with $\sim 80 \%$ of these totals caught on just four nights of each lunar sampling. Large cohorts (November 1998, December 1999) were reduced to 100 potential settlers, selected in proportion to their abundance and sizes in each trap, while all settlers were analyzed from the other cohorts. Divers collected 345875 recruits in different months (Table A1). As most of these collections contained recruits from several lunar cohorts, we used a preliminary growth curve to isolate fish from the target cohorts (see Vigliola and Meekan 2002 for more detail). Initially, 100 recruits were selected from the mixed-age collections in proportion to their abundance within the appropriate size range. As these ranges were designed to be inclusive of the full range of growth rates for each cohort, subsequent age estimation revealed individuals that were not part of the desired cohorts. These individuals were removed prior to analysis, so that our monthly samples of recruits ranged from 61 to 98 (Table A1).

\section{Otolith analysis}

Otoliths from 991 fish were excised and analyzed following the methods of Vigliola and Meekan (2002). Briefly, lapillae were removed, mounted on glass slides, ground on lapping film to produce thin transverse sections containing the nucleus, and viewed under transmitted light with immersion oil at $1000 \times$ magnification. Daily increments within each otolith were measured to the nearest $1 \mu \mathrm{m}$ along the longest axis of each section using an image analysis system. Daily deposition of increments in this species has been validated by a tag-recapture study (A. Hansen and A. Retzel, unpublished data). However, we assumed that the increment closest to the core of each otolith was formed on the day of hatching (e.g., Campana and Neilson 1985).

The SL of each fish on every day between hatching and capture was back calculated from its otolith using the linear biological intercept method (Campana 1990), which assumes that otoliths grow in proportion to body length (Vigliola et al. 2000). Evidence for this assump- tion is provided by the strong linear relationship between otolith radius and fish length for this species (Vigliola and Meekan 2002). The biological intercept was set at hatching where mean otolith radius and fish size were estimated at $9.4 \mu \mathrm{m}$ and $2.3 \mathrm{~mm} \mathrm{SL}$, respectively (Vigliola and Meekan 2002).

Two-factor (cohort and time) nonlinear mixed-effects (NLME) models (Pinheiro and Bates 2000) were used to compare the estimates of growth trajectories back calculated from the otoliths of fish surviving to different ages. These models have recently been developed to examine longitudinal, unbalanced, and autocorrelated data sets, characteristics that are typical of data extracted from fish otoliths (Chambers and Miller 1995). To investigate differences in growth rates before and after settlement $\left(t_{x}\right)$, we fitted a parabolic model (after Vigliola 1998) to larvae,

$$
L_{(t)}=L_{0}+K_{1} t^{2} \quad \text { for } t \leq t_{x}
$$

and a standard von Bertalanffy function (Quinn and Deriso 1999) to juveniles,

$$
L_{(t)}=L_{\text {asym }}\left[1-e^{-K_{2}\left(t_{2}-t_{0}\right)}\right] \quad \text { for } t>t_{x}
$$

where $L_{(t)}$ is standard length (mm) at age $t$ (in days), $L_{0}$ is length at hatching, $K_{1}$ is growth acceleration $\left(\mathrm{mm} / \mathrm{d}^{2}\right)$, $L_{\text {asym }}$ is average length at the end of asymptotic growth period, $K_{2}$ is instantaneous growth (percent per day), $t_{0}$ is the predicted age when individuals have a length of zero, and $t_{x}$ is the age at transition between larval and juvenile stages such that

$$
L_{x}=L_{0}+K_{1} t_{x}^{2}=L_{\text {asym }}\left[1-e^{-K_{2}\left(t_{x}-t_{0}\right)}\right]
$$

for the two curves to intersect at the point $\left(L_{x}, t_{x}\right)$. Larval and juvenile growth parameters were estimated setting $t_{x}=12 \mathrm{~d}$ (the age of the youngest settler) as first approximation in Eqs. 1 and 2. The exact point of intersection between the two growth curves was then determined a posteriori by solving Eq. 3 using numerical optimisation (Nocedal and Wright 1999). The parabolic growth model (Vigliola 1998) is based on the assumption of proportionality between somatic growth and fish age. Theoretical justification of this model is based on feeding behavior during the planktonic larval stage. After hatching fish larvae need to learn which prey they can successfully capture and how to attack them, so that the rate of feeding success and hence growth rate will increase with age (Kentouri and Divanach 1982).

Correlation analyses were used to examine the strength and timing of size-selective mortality in relation to body size, growth rates, and fish densities. The intensity of natural selection (SI) was measured as the difference in trait means before and after selection standardized by the standard deviation before selection (Brodie et al. 1995)

$$
\mathrm{SI}=\frac{(\overline{\text { Trait }})_{\text {after }}-(\overline{\text { Trait }})_{\text {before }}}{\mathrm{SD}_{\text {before }}} .
$$


Standard length at $12 \mathrm{~d}$ was the trait on which the strength of selection was estimated.

\section{Molecular analysis}

Otoliths revealed the strongest phenotypic selection in the November 1998 cohort. Consequently, this cohort was selected for molecular analysis. DNA from individuals used in the otolith analyses was extracted from muscle tissue using a 10\% Chelex (BioRad Laboratories, Hercules, California, USA) solution (Walsh et al. 1991). A fragment of the putative mitochondrial control region was then amplified using primers CR-A and CR-E (Lee et al. 1995). Hotstart thermocycling parameters using Amplitaq DNA polymerase consisted of an initial hold at $80^{\circ} \mathrm{C}$ followed by 39 cycles of $94^{\circ} \mathrm{C}, 30 \mathrm{~s}, 50^{\circ} \mathrm{C}, 30 \mathrm{~s}$, $72^{\circ} \mathrm{C}, 45 \mathrm{~s}$, and a final 5 -min extension. PCR products were visualized on a $1 \%$ agarose gel and enzymatically prepared for sequencing through incubation with ExonucleaseI (5 units; Amersham Biosciences Corporation, Arlington Heights, Illinois, USA) and Shrimp Alkaline Phosphatase (0.5 units; Amersham) at $37^{\circ} \mathrm{C}$ for $30 \mathrm{~min}$ followed by denaturation at $80^{\circ} \mathrm{C}$ for $15 \mathrm{~min}$. Cycle sequencing was done with ABI BigDye 3.0 chemistry (Applied Biosystems, Foster City, California, USA) using the above PCR primers. Sequencing products were analyzed on an ABI 377 automated sequencer (Applied Biosystems); forward and reverse sequences were proofread and compiled in Sequencher 4.0 (GeneCodes Corporation, Ann Arbor, Michigan, USA). Alignments were performed using ClustalW (Thompson et al. 1994) then modified by eye. MacClade 4.05 (Maddison and Maddison 2002) was used to format the sequences and merge identical haplotypes for use by Arlequin (Schneider et al. 2000).

Genetic differentiation resulting from size-selective mortality was examined by treating settlers and recruits as distinct temporal populations, and comparing their genetic structure using $\phi_{\mathrm{ST}}$ as calculated in Arlequin (Schneider et al. 2000) with statistical significance determined through 3000 random permutations. To explore the effects of the different sizes of the settler and recruit samples, 68 fish (the size of the recruit sample) were selected randomly from the 91 settlers 500 times and the $\phi_{\mathrm{ST}}$ values between groups calculated in Arlequin. To further explore the effects of genetic drift caused by high mortality, $10,20,30,40,50,60$, or 70 fish were removed at random from the settler sample, representing up to $77 \%$ mortality. This sample of remaining "survivors" was then compared to the original settler sample to determine the range of $\phi_{\mathrm{ST}}$ values resulting from high, but random, mortality. For each removal class, a distribution was created from 1000 iterations of random removals to determine the probability of genetic drift producing the observed results.

The relationship between genetic structure and sizeselective mortality was further explored by manipulating selection intensity a posteriori such that the settler and recruit samples were made more similar or more different in (1) size at hatching, (2) size at settlement (12 d), and (3) larval growth. Size selective mortality was imposed to widen the phenotypic difference between temporal samples by removing the 10,20 , or 30 smallest/slowest fish from the recruit sample and/or removing the 10,20, or 30 largest/fastest fish from the settler sample. Size selective mortality was then imposed to minimize the phenotypic differences between samples through the opposite treatments: i.e., removing the 10 , 20 , or 30 smallest/slowest fish from the settler sample, and/or removing the 10,20 , or 30 of the largest/fastest fish from the recruit sample. To control for potential sample size effects, the same number of randomly selected individuals was removed simultaneously from the non-treatment group. In total, 12 a posteriori experimental treatments were performed. Because Arlequin only indicates $\phi_{\mathrm{ST}}$ values significantly larger than zero, a simulation was performed for each trait in which 10,20 , or 30 individuals were removed at random from both data sets. The resulting $\phi_{\mathrm{ST}}$ values from 1000 iterations formed a distribution from which values significantly larger than the $\phi_{\mathrm{ST}}$ obtained from natural selection alone could be determined and represent a further test for genetic drift within the cohort.

\section{Results}

\section{Light trap catches}

A total of 694 Neopomacentrus filamentosus larvae were collected during the 1998/1999 and 1999/2000 spawning seasons with most fish collected from late spring to early summer (October to December) in both years. The average size of potential settlers was 11.16 $\mathrm{mm} \mathrm{SL}(\mathrm{SD}=0.89 \mathrm{~mm}$, range $=7.70-13.80 \mathrm{~mm})$ and the average age of a representative sample of 345 fish was 18 days $(\mathrm{SD}=3 \mathrm{~d}$, range $=12-27 \mathrm{~d})$. Larval supply was highly variable among cohorts with total catches ranging between 0 and 381 potential settlers (Appendix A: Table A1).

\section{Comparison of larval growth trajectories among cohorts}

Parabolic models provided equally good fits to the first 12 days of larval growth for all four cohorts, whether back calculated from settlers or three-month recruits (Fig. 1). Comparisons of the coefficients of the NLME model indicated that cohorts at three months after settlement were composed of fish that were significantly bigger at hatching (Fig. 2A; two-way ANOVA, $\left.F_{1,624}>12.79, P<0.001\right)$, had grown significantly faster as larvae (Fig. $2 \mathrm{~B} ; F$ tests for linear combinations, $\left.F_{1,7569}>19.23, P<0.001\right)$, and were larger at $12 \mathrm{~d}$ (Fig. 2C; two-way ANOVA, $F_{1,624}>$ 20.76, $P<0.001)$ than their initial composition when sampled at settlement, albeit with significant interactions for starting size and growth rate (Appendix B: Table B1). Qualitatively, all four cohorts were modified in the same way, with three months of post-settlement mortality selectively eliminating individuals with the smallest starting sizes and the slowest growth rates. 


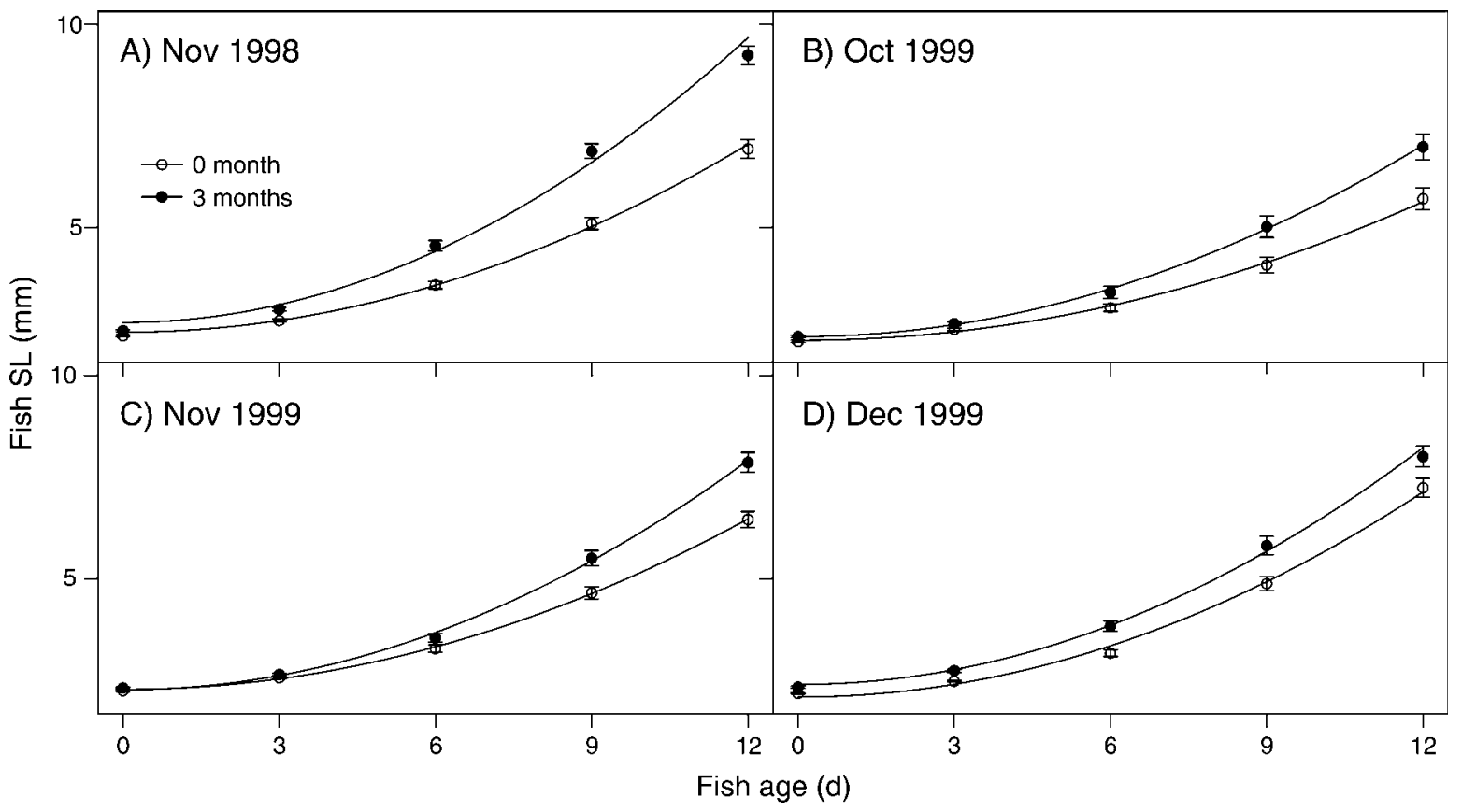

FIG. 1. Comparison of parabolic growth models fitted by nonlinear mixed effects (NLME) during the planktonic larval stage of four cohorts (November 1998, October 1999, November 1999, and December 1999) of Neopomacentrus filamentosus sampled at two times ( 0 and 3 months after settlement). Data are mean standard length (SL; the distance from the tip of the snout to the base of the caudal fin), with error bars indicating 95\% CI. Means are only shown every three days for clarity.

Effect size varied among cohorts. For example, settlers from the December 1999 cohort had smaller hatch sizes than settlers from the previous month (Fig. 2 A; two-way ANOVA, $\left.F_{1,624}>14.37, P<0.001\right)$ but no differences in hatch sizes were detected between the recruit samples from these same cohorts (two-way ANOVA, $F_{1,624}<1.75, P>0.18$ ). Larval growth rates from the same cohorts showed the opposite pattern. Settlers from the December 1999 cohort recorded faster growth than settlers from the November 1999 cohort ( $F$ tests for linear combinations, $F_{1,7569}>23.42, P<$ $0.0001)$, but this difference was erased by the time both cohorts were three months old (Fig. 2B, $F$ tests for linear combinations, $\left.F_{1,7569}<0.91, P>0.34\right)$. In contrast, settlers from the December 1999 cohort also had faster growth than settlers from the November 1998 cohort $(F$ tests for linear combinations, $F_{1,7569}>6.36, P<0.05$ ) but recruit samples from the same cohorts showed a bigger difference in the opposite direction ( $F$ tests for linear combinations, $\left.F_{1,7569}>56.92, P<0.001\right)$.

While some of these exact comparisons involve tiny differences in the model parameters that may arise from chance or parameter estimation, the overall pattern is one of consistent modification of cohort composition at, or after, settlement from selective mortality against small and/or slow-growing individuals. The large effect size observed in all three model parameters for the November 1998 cohort (Fig. 2A-C) compared with all three cohorts from 1999 (except that for hatch size in the
December 1999 cohort) shows that the strength of size selection is not constant.

\section{Comparison of larval growth trajectories within cohorts}

Two cohorts (November 1998, November 1999) were resampled more than once yielding information about the evolution of the patterns described above (Fig. 2DF). As before, interaction terms were significant for both parameters of the parabolic larval growth model (Appendix B: Table B1) fitted to the crossed factors of cohort (November 1998, November 1999) and age (settlers, recruits sampled at one, two, and three months after settlement). Comparisons of model coefficients for the November 1998 cohort showed no modification of hatch sizes between settlers and recruits at one month (two-way ANOVA, $F_{1,681}<1.09, P>0.29$ ), but progressive modification of this cohort over the next two intervals (Fig. 2D). The hatch sizes of recruits two months after settlement were larger than those of recruits at one month (two-way ANOVA, $F_{1,681}>$ $32.09, P<0.001$ ), and the hatch sizes of recruits three months after settlement were larger than those of recruits at two months (two-way ANOVA, $F_{1,681}>$ 4.68, $P<0.04)$. In contrast, hatch sizes in the November 1999 cohort did not differ between settlers and recruits up to two months after settlement (two-way ANOVA, $F_{1,681}<2.96, P>0.08$ for all comparisons). However, hatch sizes in the oldest recruit sample (three months) were significantly larger than in earlier samples of this cohort (two-way ANOVA, $F_{1,681}>15.24, P<0.001$ ). 


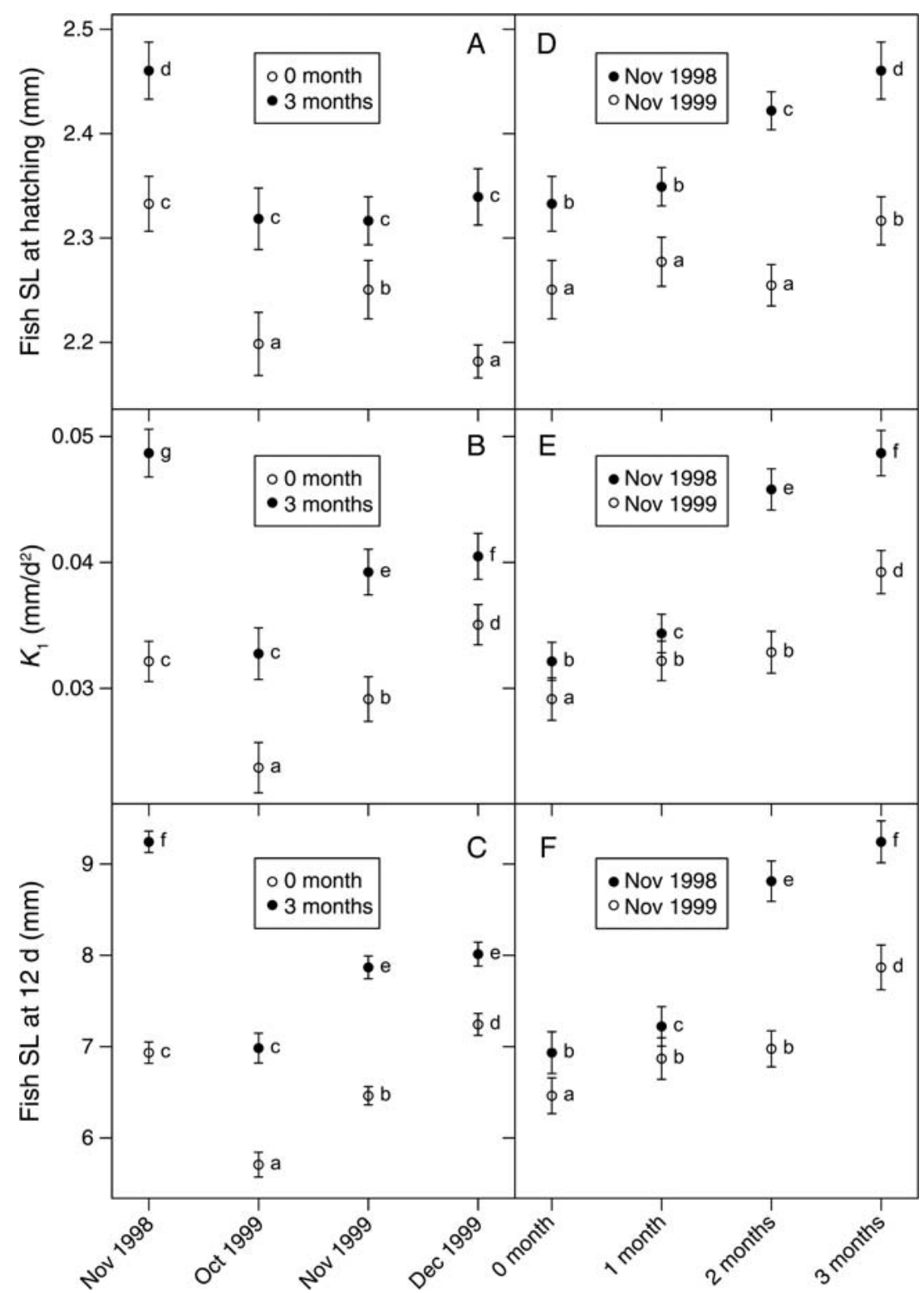

FIG. 2. Comparison of planktonic growth parameters of (A, B, C) four cohorts (November 1998, October 1999, November 1999, and December 1999) of Neopomacentrus filamentosus sampled at two times (0 and 3 months after settlement) and (D, E, F) two cohorts (November 1998 and 1999) sampled at four times (0, 1, 2, and 3 months after settlement). (A, D) Fish standard length (SL) at hatching compared by MANOVAs; (B, E) parabolic growth acceleration $K_{1}$ compared by nonlinear mixed-effects (NLME) models; (C, F) fish standard length at 12 days compared by MANOVA. Different lowercase letters indicate differences at $P<0.05$. Error bars show $95 \% \mathrm{CI}$.

Average larval growth rates (Fig. 2E) increased with each resampling of the November 1998 cohort $(F$ tests for linear combinations, $\left.F_{1,8253}>4.06, P<0.05\right)$. In the November 1999 cohort, larval growth rates in the settler sample were slower than those in the first two collections of recruits $\left(F\right.$ tests for linear combinations, $F_{1,8253}>$ 10.57, $P<0.01)$, but did not differ between the latter collections $\left(F\right.$ tests for linear combinations, $F_{1,8253}<$ $0.35, P>0.55)$. Both were slower, however, than larval growth rates recorded in recruits collected three months after settlement ( $F$ tests for linear combinations, $F_{1,8253}$ $>40.65, P<0.001)$.

Quantitative comparisons of larval size at $12 \mathrm{~d}$ produced the same outcomes as those described for growth rates (cf. Fig. 2E, F) and size-at-age plots confirm that these differences can be traced back to hatch sizes (Fig. 3A, B). This is clearest in trajectories from the November 1998 cohort, where there was strong selection on recruits between one and two months after settlement. 
Nov 1998
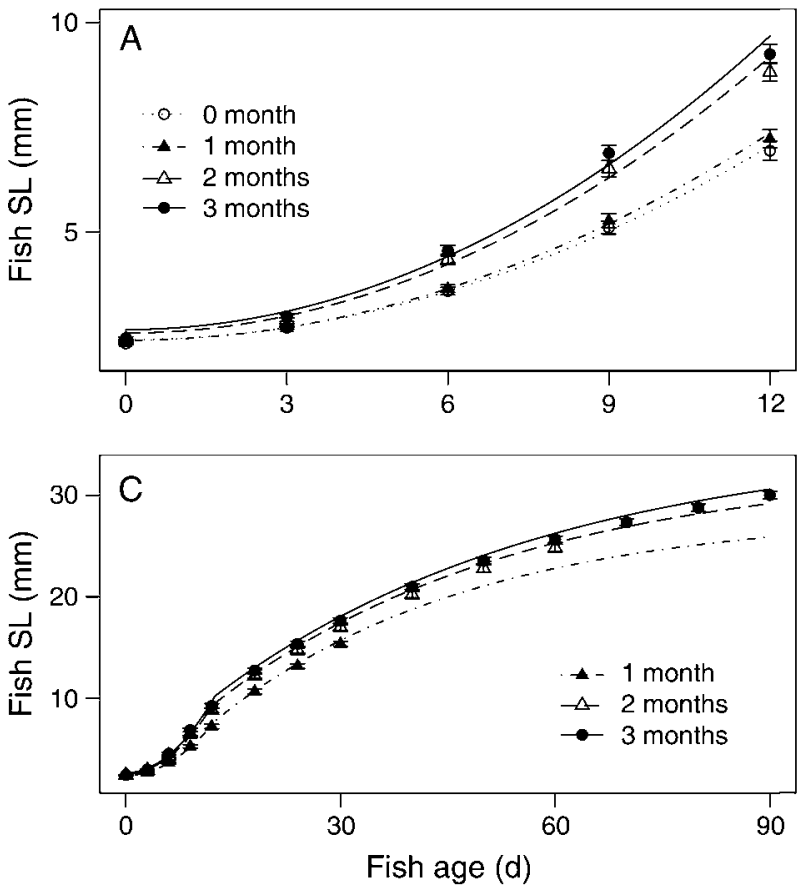

Nov 1999
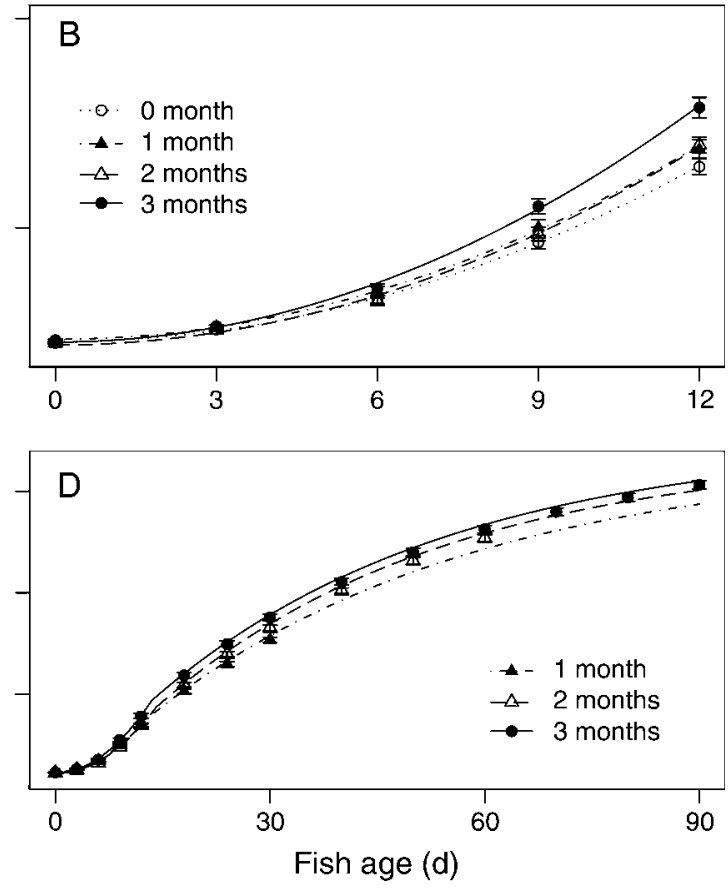

FIG. 3. Comparison of growth models fitted by nonlinear mixed-effects (NLME) models for two cohorts (November 1998 and 1999) of Neopomacentrus filamentosus sampled at four times (0, 1, 2, and 3 months after settlement). (A, B) Presettlement parabolic and (C, D) post-settlement Von Bertalanffy growth models for (A, C) November 1998 and (B, D) November 1999. Error bars indicate $95 \%$ CI. Means are only shown every 3, 6, or 10 days for clarity.

\section{Comparison of juvenile growth trajectories within cohorts}

Interaction terms were significant for both parameters of the von Bertalanffy growth model (Appendix B: Table B1) fitted to the crossed factors of cohort (November 1998, November 1999) and age (recruits at one, two, and three months after settlement), showing that recruits from both cohorts had different backcalculated growth trajectories when sampled at different times after settlement (Fig. 3C, D). The parameters of this model indicated that these differences were largely the propagation of differences present during larval life. A significant interaction term for the intercept $t_{0}$ of the model was consistent with changing mean size at settlement, albeit with differences between the two cohorts. The stronger selection evident on the November 1998 cohort was reflected in greater changes in postsettlement growth rate (Fig. 4A) and consistent elevation of predicted final size at the end of the study (Fig. 4B). In contrast, the November 1999 cohort showed less change in both parameters with significant change in $L_{\text {asym }}$ detected only at the final sampling. For the six samples for which we could estimate both a parabolic larval and a von Bertalanffy juvenile growth models (November cohorts at one, two, and three months after settlement), numeric optimization of Eq. 3 revealed an exact age at transition close to 12 days $(12.9 \pm 0.7 \mathrm{~d}$, mean $\pm \mathrm{SD}$; range $12-14 \mathrm{~d}, n=6$ ).

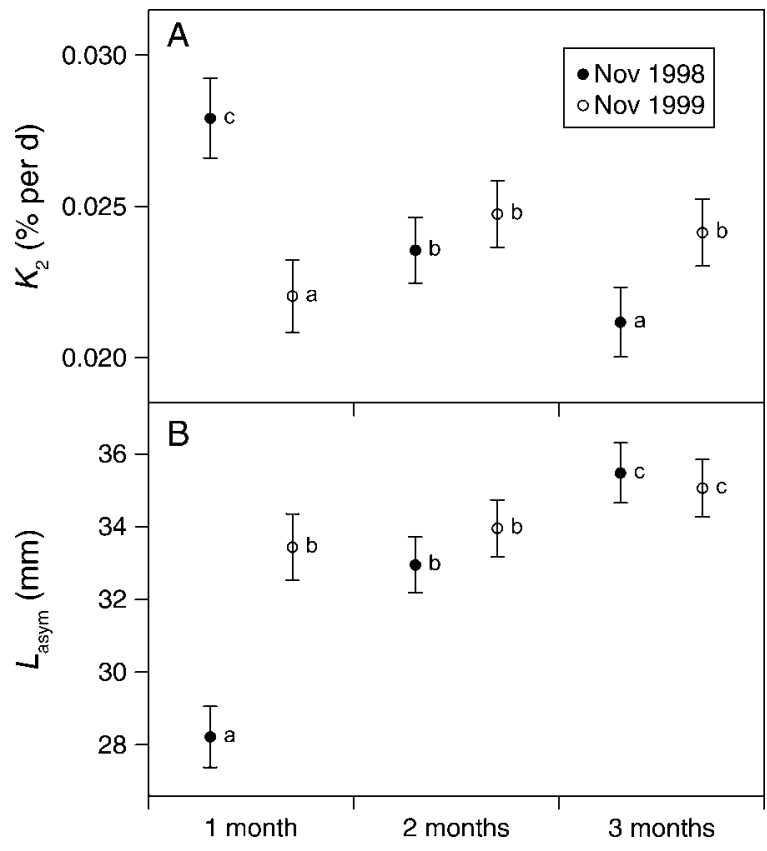

FIG. 4. Comparison of post-settlement growth parameters of two cohorts (November 1998 and 1999) of Neopomacentrus filamentosus sampled at three times $(1,2$, and 3 months after settlement). (A) Von Bertalanffy relative growth rates $K_{2}$ and (B) asymptotic lengths at the end of the study $L_{\text {asym }}$ (based on standard length, SL) are compared by nonlinear mixed-effects (NLME) models. Different lowercase letters indicate significant differences at $P<0.05$. Error bars indicate $95 \% \mathrm{CI}$. 


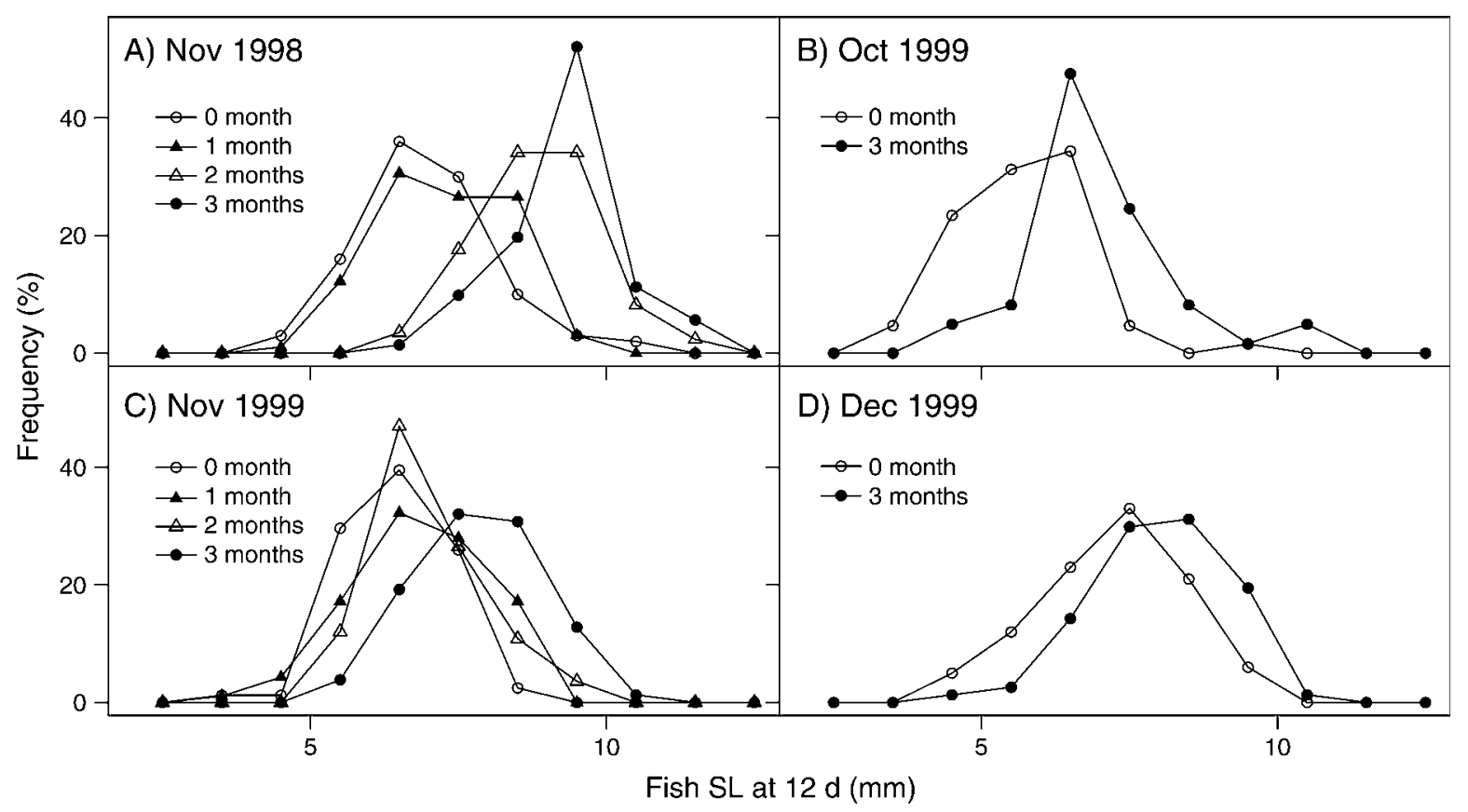

FIG. 5. Size (SL, standard length) frequency distributions at age 12 days estimated for fish from four cohorts of Neopomacentrus filamentosus collected $0,1,2$, and 3 months after settlement.

\section{Variability in the timing and strength of size-selective mortality}

Analysis using NLME models of growth trajectories showed that size-selective mortality occurred in all cohorts, with smaller individuals disappearing from back calculations as cohorts were sampled at longer intervals since settlement (Fig. 5). Significant cohort-byage interactions in all analyses (Appendix B: Table B1) indicated that the strength of size selection varied both among cohorts and sampling intervals. Selection intensity (SI) was strongest in the November 1998 cohort (SI $=2$ ), lowest in the December 1999 cohort ( $\mathrm{SI}=0.6)$, and intermediate in the other cohorts. Although selection intensity was not correlated with planktonic growth rate $(r=-0.16, P=0.58)$, it was positively correlated with the magnitude of light trap catches $(r=0.65, P=0.17)$ implying a link with the density of settlers, albeit not one arising immediately after settlement. In the November 1998 cohort, the strongest episode of size-selective mortality occurred between one and two months after settlement, at an average size of $23 \mathrm{~mm}$ SL, while a similar episode in the November 1999 cohort occurred a month later at an average size of $29 \mathrm{~mm}$ SL.

\section{Genetic selection}

A total of 365-533 bp of mitochondrial control region DNA sequence was obtained for 91 settlers and 68 recruits collected three months after settlement from the November 1998 cohort. These yielded a total 145 unique haplotypes (82 and 67 for settler and recruits, respectively, with four shared between samples). Genetic structure among the two samples was slight, but significant $\left(\phi_{\mathrm{ST}}=0.016, P=0.041\right)$, indicating temporal genetic structure. In contrast to differences resulting from natural selection, 500 replicate trials comparing a random assortment of 68 settlers to the original 91 setters resulted in no $\phi_{\mathrm{ST}}$ values statistically different from zero. Removing 10, 20, 30, 40, 50, and 60 larvae at random from the settlers resulted in no significant $\phi_{\mathrm{ST}}$ values when compared to the original settler sample. Only when 70 (77\%) of the larvae were randomly removed were two significant $\phi_{\mathrm{ST}}$ values obtained, indicating $P=0.004$ of getting a significant $\phi_{\mathrm{ST}}$ by genetic drift.

Augmenting selective pressure by removing the smallest and slowest growing individuals from the recruit sample increased the phenotypic difference among settler and recruit samples as well as the magnitude and significance of $\phi_{\mathrm{ST}}$ values for both size at day 12 and growth rate, but not size at hatching where additional selective pressures had equivocal effects (Fig. 6A-C; Appendices C-E: Tables C1, D1, and E1). Furthermore, these increased $\phi_{\mathrm{ST}}$ values were larger than $\phi_{\mathrm{ST}}=0.016$ resulting from natural selection alone as determined by the distribution resulting from 1000 random permutations where 10,20 , or 30 individuals were removed at random from both samples. Selective removals of larger, faster growing fish from the settler sample also increased the phenotypic difference between settler and recruits, yielding larger and more significant $\phi_{\mathrm{ST}}$ values that were significantly larger than $\phi_{\mathrm{ST}}=0.016$ resulting from selection alone (Fig. 6D-F; Appendices C-E: Tables C1, D1, and E1). 


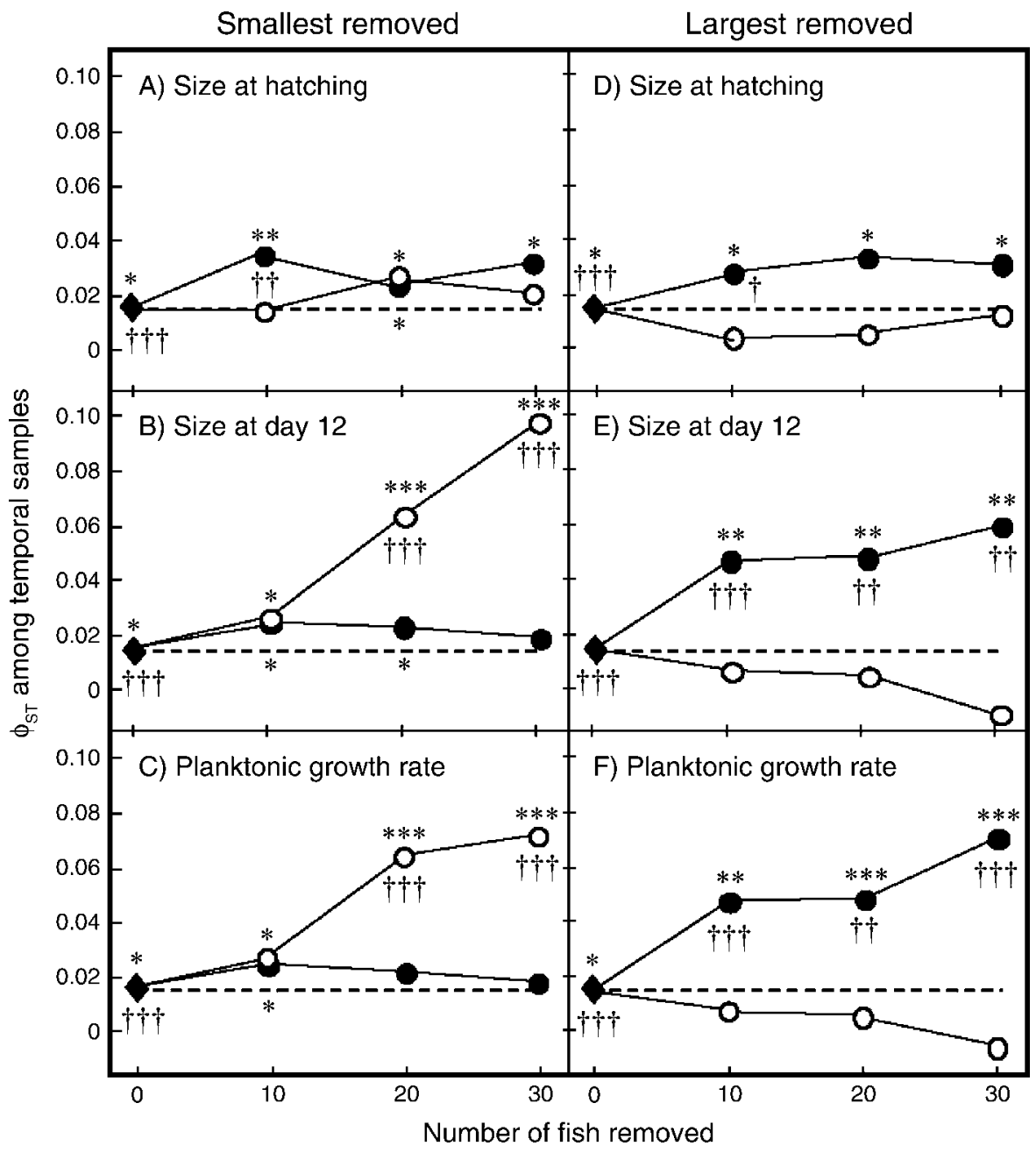

FIG. 6. Relationship between $\phi_{\mathrm{ST}}$ and strength of selection for Neopomacentrus filamentosus based on size at hatching, size at day 12, and growth rate. Diamonds represent the initial $\phi_{\mathrm{ST}}=0.016$ obtained from Arlequin (Schneider et al. 2000). Open circles indicate $\phi_{\mathrm{ST}}$ values resulting from augmented selection in which the 10,20 , or 30 (A, B, C) smallest/slowest-growing fish or (D, E, F) largest/fastest-growing fish were removed from the three-month-old recruit samples and compared to the settlers in which 10, 20, or 30 fish were removed at random. Solid circles represent the same treatment but with selection imposed upon the settlers with random removal from the three-month recruit sample. Asterisks indicate values greater than 0 at levels $* P<0.05$; ${ }^{* *} P<0.01$; and $* * * P<$ 0.001 as obtained from Arlequin. Daggers indicate values significantly greater than $\phi_{\mathrm{ST}}=0.016$ at levels of $\dagger P<0.05, \dagger \dagger P<0.01$, and $\dagger \dagger \dagger P<0.001$ as obtained from 1000 random permutations. Exact values are given in Appendices C-E: Tables C1, D1, and E1.

Removing the smallest and slowest growing individuals from the settler sample decreased the phenotypic difference among settler and recruit samples, but $\phi_{\mathrm{ST}}$ values were still significantly larger than zero for most comparisons. However, with the exception of the treatment that removed 10 of the individuals that were smallest at hatching, none of these values were significantly different than $\phi_{\mathrm{ST}}=0.016$ resulting from selection alone (Fig. 6A-C; Appendices C-E: Tables C1, D1, and E1). Similarly, the removal of the larger, faster growing fish from the recruit sample also decreased the phenotypic difference between settler and recruits. In this case, $\phi_{\mathrm{ST}}$ value decreased in magnitude and/or became nonsignificant (Fig. 6D-F; Appendices C-E: Tables C1, D1, and E1).

\section{Discussion}

\section{The settlement transition and predation risk}

Settlement is a critical transition in the life history of all benthic marine organisms with complex life cycles and dispersive larvae denoting the shift from planktonic to demersal lifestyles (Roughgarden et al. 1988). For most species, it is an abrupt transition requiring the rapid acquisition of new adaptations and the loss of old ones with the most extreme manifestation being the radical metamorphoses of invertebrates. Conversion to sessile life is an irrevocable choice with profound consequences for subsequent reproduction (Moran and Emlet 2001, Phillips 2002) because it is not unusual for settlement to be followed immediately by very high, even catastrophic, 
mortality (Caffey 1985, Gosselin and Qian 1997a,b). Metamorphic invertebrates with small body sizes and little time to grow defensive adaptations are vulnerable to a wide range of mortality sources, including physiological stresses (Schmidt et al. 2000), predation (Hunt and Mullineaux 2002), and even removal by indiscriminate grazing (Sammarco 1980, Barnes 1999).

While the metamorphosis of benthic fish larvae may be less spectacular than those of invertebrates, settlement is still a period of rapid physiological, behavioral, and ecological change (Kaufman et al. 1992, McCormick and Makey 1997). Many species adopt sedentary lives after settlement (Sale 1978), so there are parallels with sessile forms and habitat selection is no less evident or important (e.g., Wellington 1992). Research on tropical and temperate reef fishes has highlighted the critical importance of predation during (Doherty et al. 2004) and following (Webster 2002) settlement, when naïve metamorphs are still adapting to their benthic environment (McCormick et al. 2002). Consequently, settlement can be a time of intense natural selection upon traits affecting individual fitness.

Size selective mortality in Neopomacentrus filamentosus

Neopomacentrus filamentosus is a planktivorous damselfish that settles gregariously with conspecifics. At the neighborhood level, prey clumping can attract predators (Hixon 1991) so that per capita mortality of prey in dense clumps is higher than those with more uniform distributions even when total abundance is higher in the latter (Brunton and Booth 2003). While schooling is a defense against predation, it can also reduce individual fitness because bony fish have plastic growth rates (van Rooij et al. 1995) and social interactions in fish schools of mixed age often results in growth suppression of subordinate individuals, especially at higher densities (Doherty 1982, Booth 1995, Webster 2004).

The key ecological result from our study was that postsettlement mortality in four lunar cohorts of Neopomacentrus filamentosus was consistently selective against the smallest and slowest-growing individuals in each cohort during the first three months of benthic life. The timing and intensity of size selection varied between the two cohorts that were resampled more than once (November 1998, November 1999) and the strongest size selection was observed in the cohort with highest initial density. These results are consistent with density-dependent mortality selecting against individual variation.

Neopomacentrus filamentosus collected from the water column before settlement showed substantial phenotypic variation. Their ages ranged from 12 to 27 days and their sizes from 7.7 to $13.8 \mathrm{~mm}$. Despite this variation, the majority of live individuals had the silver pigmentation typical of metamorphs suggesting that all were developmentally competent to settle. Since we did not measure the biochemistry of these presettlement fish, we cannot exclude linked selection for condition factors other than larval growth (Kerrigan 1996). While this might have been an issue if we had not detected any phenotypic selection, there was a clear and significant disadvantage to small size and/or slow growth rate in newly settled individuals.

The current paradigm for recruiting reef fish is one of greatest mortality immediately after settlement (Hixon and Webster 2002), whereas we detected size selection between one and two months after settlement that coincided with an ontogenetic shift in microhabitat. Settlers shelter initially around the bases of coral "bommies" but later migrate up to the tops of these structures where they join mixed age groups foraging higher in the water column. This is when competitive interactions with older conspecifics have greatest potential for facilitating selective predation (Brunton and Booth 2003, Webster 2004). The micro-habitat segregation evident at settlement may be a strategy to reduce this conflict at the time when new colonists are most vulnerable. Finn and Kingsford (1996) describe similar habitat segregation and ontogenetic movement during the phased colonization of coral reefs by schooling cardinalfish, which are preferred prey of many piscivores (Webster and Almany 2002).

A lack of detectable size selection in the first month after settlement must not be confused with low mortality. The basis of our test was longitudinal resampling of a cohort to recover the characteristics of survivors (Sogard 1997) and was designed explicitly to capture evidence of size selection. As such, it is based on relative abundance of growth phenotypes and is silent about mortality that does not alter size structure. Doherty et al. (2004) found instantaneous mortality of $60 \%$ during settlement of a tropical surgeonfish that was not size selective and would be missed by this analysis. This may be typical of mortality that is brief and/or dependent upon random encounter between predator and prey, unlike the selective mortality observed in dense clumps of sizestructured prey (Brunton and Booth 2003).

Sogard (1997) points out that high mortality is one of three necessary conditions for the detection of size selection because low non-random mortality may not detectably modify the size distribution of survivors. This could explain the different pattern of size selection seen in the November 1999 cohort of Neopomacentrus filamentosus, which was mostly expressed in fish between two and three months of age. While this cohort settled at $20 \%$ of the density of the November 1998 cohort, it was composed of smaller fish with slower growth histories before settlement, which is indicative of cooler water temperatures (Meekan et al. 2003). Unfortunately, we do not have independent environmental data, but a cooler year resulting in slower pre- and post-settlement growth could explain why the ontogenetic migration to higher positions in the water column was delayed by a month until juveniles grew to the size to risk this transition.

\section{Temporal genetic selection}

In the cohort of highest density (November 1998), size-selective post-settlement mortality resulted in the 
generation of subtle but significant genetic structure between settlers and recruits after three months. Previous studies have reported genetic differentiation among samples of recruits (Johnson and Black 1982, Li and Hedgecock 1998, Bernardi et al. 2001) as well as between recruits and adults (e.g., Moberg and Burton 2000). These differences have been variously attributed to larvae originating from different source populations (e.g., Bernardi et al. 2001), unequal parental contribution to larval pools ( $\mathrm{Li}$ and Hedgecock 1998), and postsettlement selection (Johnson and Black 1982, Moberg and Burton 2000). In our study, we can exclude unequal parental contribution as a possible explanation because $>90 \%$ of settlers and $98 \%$ of recruits had unique haplotypes. While the cohort may have contained larvae from different sources (i.e., a Wahlund effect), the genetic changes we observed must have come either from natural selection preferring individuals with particular genotypes or from genetic drift.

A strong reduction of cohort size could alter the genetic structure of a cohort between two samples by the action of neutral genetic drift. Random sampling of the 91 settlers to produce different groups of 68 settlers for the initial comparison set did not yield significantly different $\phi_{\mathrm{ST}}$ values in 500 trials, suggesting that the observed pattern was not an artefact of reduced sample size. Furthermore, comparing the settler sample to a modified settler sample with $77 \%$ of individuals removed at random only produced two significant $\phi_{\mathrm{ST}}$ values in 1000 iterations, indicating a $0.4 \%$ probability that genetic drift alone could produce significant genetic structure, assuming similar levels of selective mortality.

In contrast, the link between size selection and genetic differentiation was corroborated by the positive relationship between the intensity of the size selection imposed a posteriori and the strength of the resulting genetic structure. Increasing the phenotypic difference between settlers and recruits, whether achieved by removing smaller/slower growing fish from the recruit sample or by removing larger/faster growing fish from the settler sample, was accompanied by a sharp and significant increase in $\phi_{\mathrm{ST}}$ values for both sizes at day 12 and growth rate, though not for size at hatching. In contrast, the reverse manipulations of the samples, removing larger/fast growing individuals from the recruit sample or small/ slower growing fish from the settler sample, decreased the phenotypic difference between temporal samples and resulted in the loss of detectable genetic structure measured by size at day 12 and/or growth rate; with equivocal results for size at hatching. In nearly all cases $\phi_{\text {ST }}$ values resulting from augmented selection significantly exceeded those resulting from random removals. These results combined with $77 \%$ mortality only having a $0.4 \%$ chance of producing significant genetic structure at random downplay the role of genetic drift in producing the observed results. Instead, it appears that the temporal genetic structure among samples was a direct function of selective mortality.
Temporal genetic selection in marine population is not uncommon (Neigel 1997). Examples include selection of allozyme alleles along salinity (Burton and Feldman 1983, Hilbish and Koehn 1985) and temperature (Rand et al. 2002) gradients. More recently, Planes and Romans (2004) detected selection against individuals in a wild cohort of fish that carried an allele linked with lower growth of fish in a laboratory experiment. Our study provides direct evidence of selection against slow growing fish but, in contrast to these previous studies, we detected this effect from comparisons of haplotypes in a non-coding region of the mitochondrial genome that is assumed to be selectively neutral.

Because the mitochondrial genome is inherited as a unit (Randi 2000), the control region is linked to other coding regions that could be under selection. As the mitochondria produces $90 \%$ of the energy for the cell, changes in mitochondrial efficiency will alter energy available for growth, creating different phenotypes to be acted upon by selection. Although the bulk of metabolic genes in the mitochondria are produced in the nucleus, mitochondrial performance can be affected by genetic variation at both nuclear and mitochondrial loci (Rawson and Burton 2002), suggesting a proximal linkage for selection of mtDNA variation and the phenotypic traits measured in this study.

Although $\phi_{\mathrm{ST}}$ responded to both size at day 12 and growth rate, results were equivocal for size at hatching. There are two potential explanations for this result. First, it may be that the back calculations of larval size become more error prone the further back they are extended, resulting in less reliable estimates. However, otolith analysis suggests otherwise, with consistent selective patterns obtained for all three traits. Hence, a more plausible explanation is that size at hatching is influenced by maternal effects (McCormick 1998, 1999, Jones and McCormick 2002). Therefore, this character may be more reflective of the reproductive condition of the female than the physiological abilities of the larvae, resulting in the absence of any discernable pattern with respect to genetic selection.

\section{Selection and the evolution of life history traits}

Life history strategies represent an ensemble of coadapted traits that collectively determine individual fitness through testing by natural selection. If, as our results indicate, post-settlement mortality is not always a chance event and faster growing individuals can have better survival after settlement, why has directional selection not purged slow growing phenotypes from these populations? The most plausible explanation involves balancing selection operating in a heterogeneous selection landscape.

There are well-documented tradeoffs among demographic traits such as growth, reproduction, and longevity (Stearns 1976). The reproduction of many marine species is characterized by high fecundity, small eggs with minimal provisioning, and planktotrophic 
larvae, which is a "risk-spreading" tactic selected by unpredictable conditions in the larval environment (Einum and Fleming 2000a,b). Total mortality is extremely high in the early life histories of such organisms and small variations in the larval environment (Houde 1987) can produce large differences in recruitment between years (Cushing 1975). When all other things are equal, maternal provisioning can enhance larval survival (Einum and Fleming 1999, Marshall and Keough 2004) but population genetics studies have shown that there is a huge variance in reproductive success among spawners that may result in genetic sweepstakes (Hedgecock 1994). While some cohorts have narrower genetic variation than their source populations, indicating very small effective population size (Turner et al. 2002), others do not, indicating that there can be many winners of the recruitment sweepstakes (Flowers et al. 2002). Some species invest in propagules of different size and quality to combine different "bet-hedging" tactics (Einum and Fleming 2004). In an unpredictable adaptive landscape, directional selection may be limited and environmental variability may reward many phenotypes sufficiently to prevent their elimination.

Hixon and Carr (1997) showed that the most intense predation on juvenile reef fishes occurs when both resident and transient piscivores target the same patch of prey. Since mobile optimal foragers should concentrate on patches offering greatest reward within their home ranges, it follows that predation pressure will not be uniform (Brunton and Booth 2003). Slow-growing individuals in a shoaling species like Neopomacentrus filamentosus face double jeopardy when they join a highdensity school of conspecifics because of the neighborhood attraction of predators and the density-dependent interactions with conspecifics that can result in growth stunting of subordinate individuals. Meanwhile, fastgrowing individuals should gain some relief from predation through the presence of more vulnerable individuals in the same school. These are benefits that cannot be easily predicted during the process of settlement and will depend upon the initial composition and densities of groups within a local neighborhood. For some species, predation can also be reduced when easier prey, like cardinalfishes, settle abundantly at the same time (Webster and Almany 2002). While fast growth is the best protection against predation, there is evidence that it comes with other costs (see review by Mangel and Stamps 2001). For example, oversize, fast growing individuals can have reduced resistance to pathogens or parasites (e.g., Desclaux et al. 2004). These and other tradeoffs will favor the retention of phenotypic plasticity and genetic diversity at the population level.

\section{Applications to marine fisheries}

Our observation of temporal genetic change in a reef fish cohort that can be linked to natural size-based selection provides two cautionary lessons. First, our discovery of linked selection on a non-coding molecular marker, the control region of mtDNA, has significance for studies that use this marker to discriminate genetic structure arising from reproductive isolation (Ferguson and Danzmann 1998). While this becomes less of an issue when sampling mixed year classes, there is potential for spatial and/or temporal differences in the intensity of size-based selection to compromise inferences about genetic stock structure in short-lived species, samples with very different year class composition, and spatial comparisons of recruitment. The use of multiple molecular markers will avoid this issue, although this is rarely done for reasons of extra cost. Under these circumstances, otolith back calculations can provide a useful cross validation that the samples are not likely to have these problems.

Beyond adding another example of non-neutral evolution of mtDNA (Ballard and Whitlock 2004), our results have implications for the management of marine fisheries if we assume that demographic variety is the evolved solution to unpredictable and variable environments. In contrast, modern fisheries are currently imposing directional selection on fish stocks through intense and consistent size-selective harvesting (Ricker 1981, Rijnsdorp 1993, Law 2000) that has the potential to eliminate the genotypes for fast growth (Heino and Godo 2002). Conover and Munch (2002) demonstrated measurable and heritable shifts in size and growth in Atlantic silversides, Menidia menidia, after just four generations of selection.

In a recent terrestrial example, Coltman et al. (2003) showed that targeted shooting of mountain sheep with the largest horns by trophy hunters had purged the population of these genotypes in a few generations, so that the original phenotypic range could not be recovered even with complete protection. While these closed remnant populations are the opposite of the open extensive populations typical of most marine organisms, there is growing evidence that modern fishing methods, which inherently target large individuals, are driving genetic structure towards genotypes for short-lived, early-maturing individuals (Heino and Godo 2002). Since the individuals removed from the gene pool (genotypes for long-lived, late-maturing individuals with high fecundity) are also those that provide most compensatory reserve in these populations (Rose et al. 2001), there is an urgent need to reconsider management regimes that encourage such selective depletion.

\section{ACKNOWLEDGMENTS}

We thank Andrew Halford, Kim Brooks, and Sylvie Trovato for field and lab work and Mireille Harmelin-Vivien and René Galzin for input in early design of the study. J. Wakely, C. Schneider, S. Palumbi, M. Sorenson, and R. Toonen provided helpful discussions that improved our treatment of the genetic data. The project was funded by the Australian Institute of Marine Science, the Australian European Award Program, le Ministère français des Affaires Etrangères, ARC-DEET, Boston University, and the National Science Foundation (Biological Oceanography, OCE 0349177). 


\section{Literature Cited}

Allen, G. R. 1991. Damselfish of the world. Mergus Press, Hong Kong.

Anderson, J. T. 1988. A review of size dependant survival during pre-recruit stages of fishes in relation to recruitment. Journal of North West Atlantic Fisheries Science 8:55-66.

Bailey, K. M., and E. D. Houde. 1989. Predation on eggs and larvae of marine fishes and the recruitment problem. Advances in Marine Biology 24:1-83.

Bakun, A., J. Beyer, D. Pauly, J. G. Pope, and G. D. Sharp. 1982. Ocean sciences in support of living marine resources: a report. Canadian Journal of Fisheries and Aquatic Sciences 39:1059-1070.

Ballard, J. W. O., and M. C. Whitlock. 2004. The incomplete natural history of mitochondria. Molecular Ecology 13:729744.

Barnes, M. 1999. The mortality of intertidal cirripedes. Oceanography and Marine Biology: An Annual Review 37: 153-244.

Bergenius, M. A. J., M. G. Meekan, D. R. Robertson, and M. I. McCormick. 2002. Larval growth predicts the recruitment success of a coral reef fish. Oecologia 131:521525 .

Bernardi, G., S. J. Holbrook, and R. J. Schmitt. 2001. Gene flow at three spatial scales in a coral reef fish, the three-spot dascyllus, Dascyllus trimaculatus. Marine Biology 138:457465.

Booth, D. J. 1995. Juvenile groups in a coral-reef damselfish: density-dependent effects on individual fitness and population demography. Ecology 76:91-106.

Booth, D. J., and D. M. Brosnan. 1995. The role of recruitment dynamics in rocky shore and coral reef fish communities. Advances in Ecological Research 26:309-385.

Brodie, E. D., A. J. Moore, and F. J. Janzen. 1995. Visualizing and quantifying natural selection. Trends in Ecology and Evolution 10:313-318.

Brunton, B. J., and D. J. Booth. 2003. Density- and sizedependent mortality of a settling coral-reef damselfish (Pomacentrus moluccensis Bleeker). Oecologia 137:377-384.

Burton, R. S., and M. W. Feldman. 1983. Physiological effects of an allozyme polymorphism: glutamate-pyruvate transaminase and response to hyperosmotic stress in the copepod Tigriopus californicus. Biochemical Genetics 21:239-251.

Caffey, H. M. 1985. Spatial and temporal variation in settlement and recruitment of intertidal barnacles. Ecological Monographs 55:313-332.

Campana, S. E. 1990. How reliable are growth backcalculations based on otoliths? Canadian Journal of Fisheries and Aquatic Sciences 47:2219-2227.

Campana, S. E., and J. D. Neilson. 1985. Microstructure of fish otoliths. Canadian Journal of Fisheries and Aquatic Sciences 42:1014-1032.

Chambers, R. C., and T. J. Miller. 1995. Statistical analysis of reconstructed life histories from otoliths: special properties of longitudinal data. Pages 155-176 in D. H. Secor, J. M. Dean, and S. E. Campana, editors. Recent developments in fish otolith research. University of South Carolina Press, Columbia, South Carolina, USA.

Coltman, D. W., P. O’Donoghue, J. T. Jorgenson, J. T. Hogg, C. Strobeck, and M. Festa-Blanchet. 2003. Undesirable evolutionary consequences of trophy hunting. Nature 426: 655-658.

Conover, D. O., and S. B. Munch. 2002. Sustaining fisheries yields over evolutionary time scales. Science 297:94-96.

Cushing, D. H. 1975. Marine ecology and fisheries. Cambridge University Press, London, UK.

Cushing, D. H. 1996. Towards a science of recruitment in fish populations. In O. Kinne, editor. Excellence in ecology. International Ecology Institute, Oldendorf/Luhe, Germany.
Desclaux, C., X. de Montaudouin, and G. Bachelet. 2004. Cerastoderma edule population mortality: role of the digenean parasite Himasthla quissetensis. Marine Ecology Progress Series 279:141-150.

Doherty, P. J. 1982. Some effects of density on the juveniles of two species of tropical territorial damselfishes. Journal of Experimental Marine Biology and Ecology 65:249-261.

Doherty, P. J. 1987. Light-traps: selective but useful devices for quantifying the distributions and abundances of larval fishes. Bulletin of Marine Science 4:423-431.

Doherty, P. J., V. Dufour, R. Galzin, M. A. Hixon, and M. G. Meekan. 2004. High mortality during settlement is a population bottleneck for a tropical surgeonfish. Ecology 85:2422-2428.

Einum, S., and I. A. Fleming. 1999. Maternal effects of egg size in brown trout (Salmo trutta): norms of reaction to environmental quality. Proceedings of the Royal Society of London, Series B: Biological Sciences 266:2095-2100.

Einum, S., and I. A. Fleming. 2000a. Selection against late emergence and small offspring in Atlantic Salmon (Salmo salar). Evolution 54:628-639.

Einum, S., and I. A. Fleming. 2000b. Highly fecund mothers sacrifice offspring survival to maximise fitness. Nature 405 : $565-567$.

Einum, S., and I. A. Fleming. 2004. Environmental unpredictability and offspring size: conservative versus diversified bethedging. Evolutionary Ecology Research 6:443-455.

Ferguson, M. M., and R. G. Danzmann. 1998. Role of genetic markers in fisheries and aquaculture: Useful tools or stamp collecting? Canadian Journal of Fisheries and Aquatic Sciences 55:1553-1563.

Finn, M. D., and M. J. Kingsford. 1996. Two-phase recruitment of apogonids (Pisces) on the Great Barrier Reef. Marine and Freshwater Research 47:423-432.

Flowers, J. M., S. C. Schroeter, and R. S. Burton. 2002. The recruitment sweepstakes has many winners: genetic evidence from the sea urchin Strongylocentrotus purpuratus. Evolution 56:1445-1453.

Gosselin, L. A., and P. Y. Qian. 1997a. Early post-settlement mortality of an intertidal barnacle: a critical period for survival. Marine Ecology Progress Series 135:69-75.

Gosselin, L. A., and P. Y. Qian. 1997b. Juvenile mortality in benthic marine invertebrates. Marine Ecology Progress Series 146:265-282.

Hare, J. A., and R. K. Cowen. 1997. Size, growth, development and survival of the planktonic larvae of Pomatomus saltatrix (Pisces: Pomatomidae). Ecology 78:2415-2431.

Hedgecock, D. 1994. Does variance in reproductive success limit effective population sizes of marine organisms? Pages 122-134 in A. Beaumont, editor. Genetics and evolution of aquatic organisms. Chapman Hall, London, UK.

Heino, M., and O. R. Godo. 2002. Fisheries-induced selection pressures in the context of sustainable fisheries. Bulletin of Marine Science 70:639-656.

Hilbish, T. J., and R. K. Koehn. 1985. The physiological basis of natural selection at the LAP locus. Evolution 39:13021317.

Hixon, M. A. 1991. Predation as a process structuring coral reef fish communities. Pages 475-508 in P. F. Sale, editor. The ecology of fishes on coral reefs. Academic Press, San Diego, California, USA.

Hixon, M. A., and M. H. Carr. 1997. Synergistic predation, density dependence, and population regulation in marine fish. Science 277:946-949.

Hixon, M. A., and M. S. Webster. 2002. Density dependence in reef fish populations. Pages 303-325 in P. F. Sale, editor. Coral reef fishes: dynamics and diversity in a complex ecosystem. Academic Press, Boston, Massachusetts, USA.

Houde, E. D. 1987. Fish early life dynamics and recruitment variability. American Fisheries Society Symposium 2:17-29. 
Hunt, H. L., and L. S. Mullineaux. 2002. The roles of predation and postlarval transport in recruitment of the soft shell clam (Mya arenaria). Limnology and Oceanography 47:151-164.

Johnson, M. S., and R. Black. 1982. Chaotic genetic patchiness in an intertidal limpet, Siphonaria sp. Marine Biology 70:157164.

Jones, G. P., and M. I. McCormick. 2002. Numerical and energetic processes in the ecology of coral reef fishes. Pages 221-238 in P. F. Sale, editor. Coral reef fishes: dynamics and diversity in a complex ecosystem. Academic Press, Boston, Massachusetts, USA.

Judson, O. P. 1994. The rise of the individual-based model in ecology. Trends in Ecology and Evolution 9:9-14.

Kaufman, L., J. Ebersole, J. Beets, and C. C. McIvor. 1992. A key phase in the recruitment dynamics of coral reef fishes: post-settlement transition. Environmental Biology of Fishes 34:109-118.

Kentouri, M., and P. Divanach. 1982. Différences et similitudes dans la genèse des comportements locomoteurs et trophiques des stades prélarvaires de Sparus auratus, Diplodus vulgaris et Diplodus sargus. Aquaculture 27:355-376.

Kerrigan, B. A. 1996. Temporal patterns in size and condition at settlement in two tropical reef fishes (Pomacentridae: Pomacentrus amboinensis and P. nagasakiensis). Marine Ecology Progress Series 135:27-41.

Law, R. 2000. Fishing, selection, and phenotypic evolution. ICES Journal of Marine Science 57:659-668.

Lee, Y.-H., T. Ota, and V. D. Vacquier. 1995. Positive selection is a general phenomenon in the evolution of abalone sperm lysin. Molecular Biology and Evolution 12:231-238.

Leggett, W. C., and E. Deblois. 1994. Recruitment in marine fishes: is it regulated by starvation and predation in the egg and larval stages? Netherlands Journal of Sea Research 32: $119-134$.

Li, G., and D. Hedgecock. 1998. Genetic heterogeneity, detected by PCR-SSCP, among samples of larval Pacific oysters (Crassostrea gigas) supports the hypothesis of large variance in reproductive success. Canadian Journal of Fisheries and Aquatic Sciences 55:1025-1033.

Maddison, W. P., and D. R. Maddison. 2002. MacClade. Sinauer Associates, Sunderland, Massachusetts, USA.

Mangel, M., and J. Stamps. 2001. Trade-offs between growth and mortality and the maintenance of individual variation in growth. Evolutionary Ecology Research 3:583-593.

Marshall, D. J., and M. J. Keough. 2004. When the going gets rough: effect of maternal size manipulation on larval quality. Marine Ecology Progress Series 272:301-305.

McCormick, M. I. 1998. Behaviorally induced maternal stress in a fish influences progeny quality by a hormonal mechanism. Ecology 79:1873-1883.

McCormick, M. I. 1999. Experimental test of the effect of maternal hormones on larval quality of a coral reef fish. Oecologia 118:412-422.

McCormick, M. I., and A. S. Hoey. 2004. Larval growth history determines juvenile growth and survival in a tropical marine fish. Oikos 106:225-242.

McCormick, M. I., and L. J. Makey. 1997. Post-settlement transition in coral reef fishes: overlooked complexity in niche shifts. Marine Ecology Progress Series 153:247-257.

McCormick, M. I., M. L. Makey, and V. Dufour. 2002. Comparative study of metamorphosis in tropical reef fishes. Marine Biology 141:841-853.

Meekan, M. G., J. H. Carleton, A. D. Mckinnon, K. Flynn, and M. Furnas. 2003. What determines the growth of tropical reef fish larvae in the plankton: food or temperature? Marine Ecology Progress Series 256:193-204.

Meekan, M. G., S. G. Wilson, A. Halford, and A. Retzel. 2001 A comparison of catches of fishes and invertebrates by two light trap designs in tropical NW Australia. Marine Biology 139:373-381.
Miller, T. J., L. B. Crowder, J. A. Rice, and E. A. Marschall. 1988. Larval size and recruitment mechanisms in fishes: toward a conceptual framework. Canadian Journal of Fisheries and Aquatic Sciences 45:1657-1670.

Moberg, P. E., and R. S. Burton. 2000. Genetic heterogeneity among adult and recruit red sea urchins, Strongylocentrotus franciscanus. Marine Biology 136:773-784.

Moran, A. L., and R. B. Emlet. 2001. Offspring size and performance in variable environments: field studies on a marine snail. Ecology 82:1597-1612.

Neigel, J. E. 1997. Population genetics and demography of marine species. Pages 274-292 in R. Ormond, editor. Marine biodiversity. Cambridge University Press, Cambridge, UK.

Nocedal, J., and S. J. Wright. 1999. Numerical optimization. Springer, Berlin, Germany.

Pauly, D., and J. MacClean. 2003. In a perfect ocean: the state of fisheries and ecosystems in the North Atlantic Ocean. Island Press, Washington, D.C., USA.

Phillips, N. E. 2002. Effects of nutrition-mediated larval condition on juvenile performance in a marine mussel. Ecology 83:2562-2574.

Pinheiro, J. C., and D. M. Bates. 2000. Mixed-effects models in S and S-plus. Springer-Verlag, New York, New York, USA.

Planes, S., and P. Romans. 2004. Evidence of genetic structure for growth in new recruits of a marine fish. Molecular Ecology 13:2049-2060.

Quinn, T. J., and R. B. Deriso. 1999. Quantitative fish dynamics. Oxford University Press, New York, New York, USA.

Rand, D. M., P. S. Spaeth, T. B. Sackton, and P. S. Schmidt. 2002. Ecological genetics of Mpi and Gpi polymorphisms in the acorn barnacle and the spatial scale of neutral and nonneutral variation. Integrative and Comparative Biology 42: $825-836$.

Randi, E. 2000. Mitochondrial DNA. Pages 136-167 in A. J. Baker, editor. Molecular methods in ecology. Blackwell Science, Oxford, UK.

Raventos, N., and E. Macpherson. 2005. Effect of pelagic larval growth and size-at-hatching on post-settlement survivorship in two temperate labrid fish of the genus Symphodus. Marine Ecology Progress Series 285:205-211.

Rawson, P. D., and R. S. Burton. 2002. Functional coadaptation between cytochrome $\mathrm{c}$ and cytochrome $\mathrm{c}$ oxidase within allopatric populations of a marine copepod. Proceedings of the National Academy of Science (USA) 99:12955-12958.

Reed, D. C., S. C. Schroeter, and P. T. Raimondi. 2004. Spore supply and habitat availability as sources of recruitment limitation in the giant kelp Macrocystis pyrifera (Phaeophyceae). Journal of Phycology 40:275-284.

Ricker, W. E. 1981. Changes in the average size and average age of Pacific salmon. Canadian Journal Fisheries and Aquatic Sciences 38:1636-1656.

Rijnsdorp, A. D. 1993. Fisheries as a large-scale experiment on life-history evolution: disentangling phenotypic and genetic effects in changes in maturation and reproduction of North Sea plaice, Pleuronectes platessa L. Oecologia 96:391-401.

Rose, K. A., J. H. Cowan., K. O. Winemiller, R. A. Myers, and R. Hilborn. 2001. Compensatory density dependence in fish populations: importance, controversy, understanding and prognosis. Fish and Fisheries 2:293-327.

Roughgarden, J., S. Gaines, and H. Possingham. 1988. Recruitment dynamics in complex life cycles. Science 241: $1460-1466$.

Sale, P. F. 1978. Reef fish and other vertebrates: a comparison of social structure. Pages 313-346 in E. S. Reese and F. J. Lighter, editors. Contrasts in behaviour. Wiley-Interscience, New York, New York, USA

Sammarco, P. W. 1980. Diadema and its relationship to coral spat mortality: grazing, competition, and biological disturbance. Journal of Experimental Biology and Ecology 45:245272. 
Schmidt, P. S., M. D. Bertness, and D. M. Rand. 2000. Environmental heterogeneity and balancing selection in the acorn barnacle Semibalanus balanoides. Proceedings of the Royal Society of London, Series B: Biological Sciences 267: 379-384.

Schneider, S., D. Roessli, and L. Excoffier. 2000. Arlequin version 2.000: a software for population genetics data analysis. User manual. University of Geneva, Switzerland.

Searcy, S. P., and S. Sponaugle. 2001. Selective mortality during the larval-juvenile transition in two coral reef fishes. Ecology 82:2452-2470.

Shima, J. S., and A. M. Findlay. 2002. Pelagic larval growth rate impacts benthic settlement and survival of a temperate reef fish. Marine Ecology Progress Series 235:303-309.

Sinclair, M. 1988. Marine populations: an essay on population regulation and speciation. University of Washington Press, Seattle, USA.

Sissenwine, M. P. 1984. Why do fish populations vary? Pages 59-94 in R. M. May, editor. Exploitation of marine communities. Springer-Verlag, Berlin, Germany.

Sogard, S. M. 1997. Size-selective mortality in the juvenile stage of teleost fishes: a review. Bulletin of Marine Science 41:423431.

Stearns, S. C. 1976. Life history tactics: a review of ideas. Quarterly Reviews of Biology. 51:3-47.

Thompson, J. D., D. G. Higgins, and T. J. Gibson. 1994. CLUSTAL W: improving the sensitivity of progressive multiple sequence alignment through sequence weighting, positions-specific gap penalties and weight matrix choice. Nucleic Acids Research 22:4673-4680.

Thorrold, S. R., and J. A. Hare. 2002. Otolith applications in reef fish ecology. Pages 243-264 in P. F. Sale, editor. Coral reef fishes: dynamics and diversity in a complex ecosystem. Academic Press, Boston, Massachusetts, USA.

Turner, T. F., J. P. Wares, and J. R. Gold. 2002. Genetic effective size is three orders of magnitude smaller than adult census size in an abundant, estuarine-dependent marine fish (Sciaenops ocellatus). Genetics 162:1329-1339.

van Rooij, J. M., J. H. Bruggemann, J. J. Videler, and A. M. Breeman. 1995. Plastic growth of the herbivorous reef fish Sparisoma viride: field evidence for a trade-off between growth and reproduction. Marine Ecology Progress Series 122:93-105.

Vigliola, L. 1998. Contrôle et regulation du recrutement des Sparidae (Poissons, Téléostéens) en Méditerranée: importance des processus pré- et post-installation benthique. Dissertation. University Aix-Marseille II, Marseille, France.

Vigliola, L., M. L. Harmelin-Vivien, and M. G. Meekan. 2000. Comparison of techniques of back-calculation of growth and settlement marks from the otoliths of three species of Diplodus from the Mediterranean Sea. Canadian Journal of Fisheries and Aquatic Sciences 57:1291-1299.

Vigliola, L., and M. G. Meekan. 2002. Size at hatching and planktonic growth determine post-settlement survivorship of a coral reef fish. Oecologia 131:89-93.

Walsh, P. S., D. A. Metzger, and R. Higuchi. 1991. Chelex-100 as a medium for simple extraction of DNA for PCR based typing from forensic material. Biotechniques 10:506-513.

Webster, M. S. 2002. Role of predators in the early postsettlement demography of coral-reef fishes. Oecologia 131: $52-60$.

Webster, M. S. 2004. Density dependence via intercohort competition in a coral-reef fish. Ecology 85:986-994.

Webster, M. S., and G. R. Almany. 2002. Positive indirect effects in a coral reef fish community. Ecology Letters 5:549 557.

Wellington, G. M. 1992. Habitat selection and juvenile persistence control the distribution of two closely related Caribbean damselfishes. Oecologia 90:500-508.

Wilson, D. T., and M. G. Meekan. 2002. Growth-related advantages for survival to the point of replenishment in the coral reef fish Stegastes partitus (Pomacentridae). Marine Ecology Progress Series 231:247-260.

\section{APPENDIX A}

Sampling dates and sample sizes (Ecological Archives E088-079-A1).

\section{APPENDIX B}

Results of nonlinear mixed effects (NLME) model analyses of growth back-calculated from otoliths of four cohorts of Neopomacentrus filamentosus (Ecological Archives E088-079-A2).

\section{APPENDIX C}

Difference in size and genetic structure between settlers and recruits based on size at hatching for both natural and augmented selection regimes (Ecological Archives E088-079-A3).

\section{APPENDIX D}

Difference in size and genetic structure between settlers and recruits based on size at day 12 for both natural and augmented selection regimes (Ecological Archives E088-079-A4).

\section{APPENDIX E}

Difference in size and genetic structure between settlers and recruits based on growth rate for both natural and augmented selection regimes (Ecological Archives E088-079-A5). 